\title{
PERCEPÇÃO DE RISCO PARA HIV/AIDS DE MULHERES FAVELADAS SEGUNDO O MODELO DE CRENÇAS EM SAÚDE*
}

\section{WOMEN LIVING IN A SLUM AND THEIR PERCEPTION ABOUT HIV/AIDS ANALISED THROUGH THE HEALTH BELIEF MODEL}

\author{
Neide de Souza Praça** \\ Dulce Maria Rosa Gualda***
}

PRAÇA, NS.; GUALDA, DMR. Percepção de risco para HIV/AIDS de mulheres faveladas segundo o modelo de crenças em saúde, Rev Esc Enf USP, v.35, n. 1,p. 54-9, mar, 2001.

\section{RESUMO}

Este estudo, com abordagem qualitativa, teve como referenciais a Antropologia Cultural e o método etnográfico. Objetivou identificar a percepção de risco de infecção pelo HIV de mulheres moradoras em uma favela. Constou de entrevistas e observação participante do contexto. Os constructos do Modelo de Crenças em Saúde foram utilizados para análise dos dados. Nesta ótica, verificou-se que as mulheres não se vêem com suscetibilidade para infectar-se pelo HIV pelos seus parceiros, situação que se modifica diante da informação da infidelidade destes, Diante desta descoberta, motivam-se a exigir medidas de proteção para evitar infecção pelo HIV no relacionamento com o companheiro.

PALAVRAS-CHAVE: Saúde da mulher. AIDS. Assistência de enfermagem.

\begin{abstract}
This paper deals with a qualitative study theoretically based on Cultural Anthropology and in the ethnographic methodology. The investigation had the aim to identify the perception of women living in a slum about the risk of HIV infection. Participant observation and interview were used for data collection. Using the concepts of the Health Belief Model the analysis showed that the women do not feel susceptibility to get HIV from their partners. They change this behavior when they have knowledge that their partner has an other woman. For this reason, they ask them to use condon in the sexual intercourse.
\end{abstract}

KEYWORDS: Woman health. AIDS. Nursing care.

\section{JUSTIFICANDO O ESTUDO}

Os dados epidemiológicos vêm demonstrando progressão no número de casos notificados de AIDS em mulheres, no Brasil. Segundo CASTILHO; SZWARCWALD (1997), esse aumento caracteriza a participação da população heterossexual, envolvendo mulheres em idade reprodutiva, especialmente jovens.

Um fator de relevância no perfil dos indivíduos infectados pelo HIV e vítimas da AIDS é abordado por BARBOSA; VILELLA (1996) ao referirem o elevado número de morte de mulheres por AIDS no Município de São Paulo no periodo de 1991 a 1993, quando 75\% tiveram essa causa. As autoras sugerem que as donas de casa são as mais atingidas. Referem, também, que $45 \%$ das mulheres com AIDS, em São Paulo, têm parceiros exclusivos.

Ao analisarmos os registros fornecidos pela Secretaria de Estado da Saúde de São Paulo (BOLETIM, 1998) referentes ao período de 1980 a

Extraído da Tese de Doutoramento "A cuidadora e o (ser)cuidado: uma relação de dependência no enfrentamento da AIDS", apresentada em 1998 à Escola de Enfermagem da Universidade de São Paulo.

** Enfermeira Obstétrica. Professor Doutor do Departamento de Enfermagem Materno-Infantil e Psiquiátrica da Escola de Enfermagem da Universidade de São Paulo. E-mail: ndspraca@usp.br

Obstetriz. Professor Associado. Diretora do Departamento de Enfermagem do Hospital Universitário da Universidade de São Paulo. E-mail: drgualda@usp.br 
1997, verificamos que o maior número de casos notificados de AIDS em mulheres teve como categoria de exposição o contato heterossexual $(48,9 \%$ do total de casos de mulheres notificados), seguido pela via sanguínea, especificamente pelas mulheres usuárias de drogas injetáveis $(26,6 \%)$. Identificamos na mesma fonte que a transmissão vertical é de $2,89 \%$ do total de casos notificados para ambos os sexos.

A par desta situação, GUIMARÃES (1996) refere-se às dificuldades da mulher em encontrar respaldo social para interpelar os maridos sobre questões referentes à segurança e à saúde. A autora exemplifica esta condição citando o resultado de um estudo que realizou na cidade do Rio de Janeiro, com mulheres HIV positivas ou soronegativas, parceiras sexuais de homens soropositivos para o virus. Identificou uma não abordagem destas mulheres junto a seus parceiros, mesmo entre aquelas que possuíam informações básicas sobre as vias de transmissão do HIV e reconheciam que seus companheiros freqüentemente se expunham a situações de risco para o vírus.

BARBOSA; VILELLA (1996) justificam o aparente desinteresse das mulheres pela preservação de sua saúde com a característica da cultura sexual brasileira que considera diferentemente a natureza do homem e da mulher. As mesmas autoras, concordes com GUIMARÃES (1996), afirmam que, neste aspecto, a mulher sente-se submetida à impetuosidade, ao gosto pela aventura e pelo prazer e à objetividade masculinos. A sensibilidade feminina, por outro lado, constitui-se em fator afetivo que se caracteriza pela passividade e pela paciência.

BARBOSA (1996), acrescenta que o "padrão sexual" brasileiro expõe a mulher a riscos de infecção pelo HIV Na maioria das vezes, ela nem percebe sua exposição. Segundo a mesma autora, nossa sociedade aceita melhor as "relações ocasionais ou extraconjugais" dos homens do que das mulheres.

BASTOS et al (1994) citam que as mulheres, principalmente aquelas com parceiros exclusivos, porque não conseguem dialogar com estes sobre medidas de sexo mais seguro, submetem-se à sua vontade quanto ao não uso do preservativo; tornamse assim mais vulneráveis à infecção pelo HIV e outras doenças sexualmente transmissiveis, pois seus companheiros, com freqüência, têm mais parceiras fora da relação, sem que suas esposas tomem conhecimento do fato. Na visão dos autores, esta situação traz implicações sociais sérias que demandam alterações no comportamento dos envolvidos, os quais precisam dialogar a respeito de sua sexualidade para melhor se protegerem.
As medidas preventivas de infecção pelo HIV, portanto, devem priorizar as mulheres com relações conjugais, onde a exclusividade dos parceiros deve atender às normas do casamento tradicional, pois, nesse contexto, é evidente o desnivel de poder entre o casal, fato que impede o afloramento de processos modificadores da identidade sexual da mulher numa abordagem sócio-cultural (BARBOSA, 1996).

GUIMARÃES (1996) analisa também as dificuldades das mulheres em conversar com seus companheiros sexuais exclusivos sobre sua sexualidade e sobre seu comportamento sexual extralar. As dificuldades estão presentes ainda na tentativa para proteger-se da infecção pelo HIV quando têm desconfianças sobre o comportamento de seus parceiros. Porém, a autora acredita que homens e mulheres acham dispensável o uso do preservativo quando as relações sexuais ocorrem entre parceiros exclusivos, pois vêem este método preventivo como mais adequado às relações ocasionais ou no início do relacionamento, principalmente como anticonceptivo. A autora discute ainda as dificuldades de negociação sobre o uso do preservativo entre a mulher e seu parceiro exclusivo.

Outro fator a considerar tem apoio no estudo de CASTILHO; SZWARCWALD (1997) que consideram ser a pauperização da epidemia, no país, outra característica da mudança do perfil da AIDS. A explicação para esta situação reside no acentuado aumento de casos da doença na população com menor grau de escolaridade. Enquanto nos anos iniciais da epidemia, os infectados com nivel de escolaridade superior ou com pelo menos o segundo grau completo eram maioria, a inversão desta característica tem sido notada a partir de meados da atual década.

Estas considerações nos levaram a realizar o presente estudo que teve como objetivo conhecer as crenças e a percepção de risco de infecção pelo HIV em mulheres residentes em uma comunidade favelada da área metropolitana da cidade de São Paulo.

\section{OPTANDO PELA METODOLOGIA}

Este estudo utilizou o método qualitativo de pesquisa. Para LÜDKE; ANDRE (1986), a pesquisa qualitativa oferece a possibilidade de o pesquisador captar a maneira pela qual os indivíduos pensam e reagem frente às questões focalizadas. Proporciona ao pesquisador conhecer a dinâmica e a estrutura da situação em estudo, do ponto de vista de quem a vivencia.

GUALDA; MERIGHI; OLIVEIRA (1995) acreditam que a pesquisa qualitativa utilizada na 
Enfermagem "contribui para a compreensão holística do homem", além de permitir explorar melhor alguns problemas sobre a assistência de Enfermagem.

As afirmações acima confirmaram-nos que, para conhecer o universo de comportamentos de grupo cultural definido, deveriamos utilizar métodos qualitativos. Assim, optamos por realizar este estudo tendo a etnografia como referencial metodológico, a qual direcionou a coleta e a análise dos dados culturais.

STREUBERT; CARPENTER (1995) referem que a exploração de culturas dentro do paradigma da Enfermagem é facilitada pela exposição do enfermeiro pesquisador no cenário cultural, pois, ao valorizar a natureza cognitiva do ser humano, tem a possibilidade de melhor compreender a dinâmica do fenômeno sob estudo e os relacionamentos presentes na cultura. Esta compreensão auxilia o enfermeiro a prestar cuidado culturalmente embasado e, portanto, proceder a intervenções mais adequadas à sua clientela.

Esta pesquisa, realizada no período de 1995 a 1998, entrevistou seis mulheres que freqüentavam um centro comunitário localizado em uma favela, na cidade de São Paulo. Estas mulheres constituíram-se nas informantes do estudo.

As informantes são, portanto, alguém, membro da sociedade em estudo, que pode contar ao pesquisador sobre suas próprias ações, crenças e sobre os padrões de comportamento que envolvem uma determinada cena/situação cultural. Aos membros da cultura cabe produzir os relatos de seu mundo, e o emprego de informantes tem sido o método básico de pesquisa na metodologia adotada. Os relatos têm seu valor ao contar-nos sobre quem os produziu e por evidenciarem as perspectivas de determinados grupos ou categorias de atores.

Neste estudo, as informantes eram moradoras da comunidade favelada, às quais prestamos assistência pré-natal, como atividade docenteassistencial, realizando consulta, orientação individual sobre cuidados com a gravidez, com o puerpério, com o recém-nascido, e visitas domiciliárias. São mulheres que nunca realizaram sorologia para o HIV e portanto desconhecem seu estado de infectividade ou não ao vírus.

Todas as entrevistas foram gravadas em fitas magnéticas e posteriormente transcritas e digitadas. Foram realizadas com o consentimento das informantes.

Para a coleta de dados foram empregadas as seguintes técnicas:
Observação participante: visa facilitar o acesso do pesquisador à comunidade, proporcionando-lhe explorar seu contexto, conhecer o modo de vida de seus membros e favorecer o desenvolvimento de um relacionamento amistoso entre aqueles e o pesquisador.

Entrevista: a entrevista com as informantes foi realizada com questão descritiva. $\mathrm{Na}$ primeira entrevista foram feitas questões abertas para que a mulher discorresse livremente sobre os temas saúde e AIDS. Posteriormente, em entrevistas subseqüentes, utilizamos questões semi-estruturadas que favoreceram um direcionamento do tema de maior interesse da pesquisa. Para direcionamento destas entrevistas, partiamos do conteúdo da(s) entrevista(s) anterior(es) de cada informante.

Pesquisa suplementar de dados: para complementar os dados das informantes, analisamos os registros feitos em seus prontuários individuais, utilizados durante as consultas de pré-natal. Esta pesquisa forneceu subsídios sobre as 282 mulheres atendidas no centro comunitário, dando idéia do coletivo do grupo cultural estudado.

A análise dos dados coletados, segundo o método etnográfico, apresenta vários passos próprios. Neste trabalho, para efetuarmos a análise dos dados, adotamos a proposta de HAMMERSLEY; ATKINSON (1990) por considerá-la a que melhor se aplica ao objetivo delineado para o estudo.

Segundo o método de análise adotado, e, similarmente a outros métodos, como ponto de partida foram feitas cuidadosas e repetidas leituras dos dados coletados, para que estes se tornassem familiares ao pesquisador. Somente após a obtenção desta familiaridade é que foi dada continuidade ao processo de análise.

O passo seguinte foi a classificação dos relatos das informantes, agrupados por afinidades de conteúdo, que passaram a constituir as categorias. Neste momento, cada segmento dos dados foi revisto e teve realçada sua relevância para uma ou mais categorias, em comparação aos outros segmentos igualmente categorizados.

O resultado da análise dos registros obtidos durante o trabalho de campo e do conteúdo das entrevistas foi validado junto às informantes, evitando, assim, possiveis distorções que pudessem ter ocorrido na interpretação que fizemos a partir dos procedimentos de coleta e de análise dos dados. 


\section{APLICANDO O MODELO DE CRENÇAS EM SAÚDE}

Nosso objetivo ao utilizar este Modelo, tendo por base os resultados culturais encontrados, visou melhor identificar os fatores, positivos ou negativos, que atuam sobre a tomada de decisão das mulheres da referida comunidade, no que diz respeito à sua saúde e à de seus familiares. Os comportamentos relacionados à transmissão do HIV/AIDS constituem-se no enfoque principal que permeou toda a trajetória do estudo.

Os dados culturais obtidos, segundo o método etnográfico de pesquisa serão aqui analisados de acordo com os pressupostos do Modelo de Crenças em Saúde.

Este Modelo oferece subsídios para análise do comportamento do individuo, segundo os seguintes constructos: suscetibilidade e severidade percebidas, relação beneficios $\mathrm{x}$ barreiras percebidas, motivação para agir e auto-eficácia. A seguir faremos breve exposição destes componentes, a fim de facilitar o entendimento do leitor.

Suscetibilidade percebida: é a percepção de um indivíduo sobre suas possibilidades de contrair um agravo à sua saúde. Varia de pessoa para pessoa.

Severidade percebida: é o grau de severidade de uma doença percebida pelo indivíduo. Depende do nível de estimulo emocional e da intensidade das perdas criados pelo pensamento de uma doença e pelas dificuldades que o indivíduo percebe que uma dada condição de saúde criará para ele.

Relação beneficios e barreiras percebidos: dependerá de como o indivíduo vê a relação entre o custo e a ação de saúde. Caso os custos sejam superiores aos beneficios derivados da ação, os procedimentos para transpor as barreiras não se efetivarão.

Motivação para agir: são fatores que influenciam a tomada de decisão do indivíduo para adotar medidas de prevenção em saúde. Dependem da relação que a pessoa faz entre a motivação para agir e as barreiras existentes para efetivação da ação.

Auto-eficácia: caracteriza-se pela convicção do indivíduo de que ele pode realizar, com sucesso, a ação que produzirá os resultados esperados.

Com esta breve definição dos componentes do Modelo de Crenças em Saúde passamos a apresentar a análise feita a partir dos dados culturais obtidos. Porém, para maior clareza do conteúdo da análise, optamos por discorrer integralmente sobre cada temática emergente dos resultados, destacando, no texto, os componentes do Modelo envolvidos no comportamento das mulheres.

\section{APRESENTANDO OS RESULTADOS}

Acreditamos que as variáveis sócio-demográficas das mulheres do grupo cultural estudado influenciam sua percepção de suscetibilidade, de severidade, de barreiras, de beneficios e de auto-eficácia que as direcionam à tomada de decisão. As mulheres dependem do que é abordado pela televisão para informar-se sobre fatos ou sobre uma doença, sendo evidente seu pouco conhecimento sobre a relação saúde-doença. Some-se a esta situação o fato de permanecerem a maior parte do dia junto aos filhos, cuidando dos afazeres domésticos, o que lhes tira a oportunidade de contatar outras pessoas e trocar informações. Esta situação acentua suas dificuldades de contato com um mundo globalizado, em constante transformação. As mulheres mantém-se voltadas para o interior das moradias e para seus familiares, sem grandes expectativas de inteirar-se com o que ocorre além destes limites.

Estas mulheres mantém relação exclusiva com seus companheiros e demonstram não se perceberem suscetiveis ao HIV para a via de transmissão sexual. Elas confiam na fidelidade de seus parceiros e acreditam que eles, assim como elas próprias, não têm relacionamentos com alguém fora de casa. Embora algumas apresentem desconfiança sobre o comportamento do companheiro quando este, desacompanhado, está em ambiente social, esta suspeita não chega a provocar preocupação para a mulher, pois ela acredita que o companheiro a informará caso tenha relacionamentos extra-lar com outra(s) mulher(s). Esta crença torna-a despreocupada e, a seu ver, afasta-a de um possivel risco de infecção.

Por outro lado, as mulheres reconhecem a severidade da AIDS para o individuo infectado e apontam como fator de agravamento o preconceito gerado no seu meio social quando em presença de alguém soropositivo para o HIV. Associam também o emagrecimento excessivo, as mudanças corporais e a morte como entidades pertinentes à severidade percebida para a doença. Embora com esta visão, as mulheres não se percebem diante de sua própria severidade para a AIDS. Consideram-se distantes da situação de soropositivas e nem mesmo cogitam tal possibilidade.

Seu nivel de informação sobre AIDS demonstra que elas possuem conhecimento deficitário sobre a doença. Ainda que informem sobre as principais vias de transmissão, o tratamento atual, o teste para triagem sorológica e o meio de prevenção da infecção, seus conceitos sobre o mecanismo de transmissão 
trazem afirmativas incompletas e nem sempre concordes, sob o ponto de vista científico. Tal situação associa o padrão de informação das mulheres da comunidade às variáveis sócio-demográficas intervenientes em seu grupo cultural.

Como barreiras percebidas pelas mulheres, destacamos sua condição de pouco poder em relação ao homem quanto ao uso de preservativo masculino, embora o reconheçam como meio preventivo da transmissão do HIV. O homem rejeita o uso do preservativo e a mulher considera descartada qualquer possibilidade de discussão sobre o tema com o parceiro, uma vez que em nenhum dos relatos analisados o termo "negociação" foi encontrado. Concluímos que a mulher respeita a opinião do companheiro e que, por depender financeira e emocionalmente dele, cogitar sobre o uso do preservativo masculino deixou de ser relevante, passando a ser ignorado e, portanto, constituindo-se em barreira intransponivel no momento. Essa condição de dependência da mulher em relação ao companheiro constitui-se em barreira que a impede de ver o preservativo masculino sob a possibilidade de uso no relacionamento exclusivo. Contrariar o parceiro poderia trazer sérios prejuízos à mulher e à família.

A condição citada acima sobrepõe-se ao valor percebido pela mulher para os beneficios que a superação das barreiras poderiam trazer-lhe. Como a mulher não se vê com suscetibilidade de infectar-se pela via sexual e nem se visualiza diante da gravidade da doença, não considera os possiveis beneficios que a tomada de decisão facilitaria obter. As mulheres desta comunidade tentam afastar-se do conflito gerado pelas imposições do companheiro que não utiliza preservativo, não abordando este assunto com ele e nem mesmo discutindo seu comportamento fora de casa. Dessa forma, esquivam-se de situações desagradáveis e consideram acertado seu baixo nível de motivação para agir.

Cabe ressaltar que, somente diante da expectativa de que serão informadas pelo companheiro quando ele mantiver relacionamento sexual com outra(s) mulher(es) é que as mulheres dessa comunidade passam a perceber-se suscetiveis ao HIV Elas consideram que somente após o comunicado sobre o fato é que correm algum risco de infectar-se. Nesta situação percebem a severidade da doença como uma transformação na aparência, caracterizada por um extremo emagrecimento que chamaria atenção de vizinhos e de pessoas de seu convívio, gerando comportamentos preconceituosos a seu respeito. Somente após identificar a quebra de fidelidade, as barreiras percebidas, até então impeditivas ao uso do preservativo, passariam a ter menor valor quando comparadas aos benefícios percebidos. A dependência econômica da mulher em relação ao homem e a influência deste sobre a não prática de sexo mais seguro passam a ter menor valor para a mulher em relação ao beneficio que advirá para sua saúde se adotar o preservativo masculino para sua proteção contra uma possivel transmissão do HIV Sob o impacto da informação, a mulher faz a relação entre barreiras e benefícios, e estes tornam-se mais poderosos motivando-as a agir mais rapidamente, passando a exigir o uso do preservativo em suas relações, por considerarem que houve comprometimento da relação do casal a partir da quebra de fidelidade de seu parceiro.

Paralelamente, o cotidiano destas mulheres é mantido distante da situação da AIDS, e como esta doença não é prioritária na vida destes casais, a maioria deles não discute sobre o tema e nem mesmo sobre o uso do preservativo, denotando prejuízo da variável auto-eficácia do Modelo de Crenças em Saúde. As mulheres, por sua vez, demonstram não se preocupar com a síndrome, delegando-a a segundo plano em sua relação familiar. Julgam que, diante da existência do fator quebra de fidelidade entre o casal, as barreiras que terão que transpor para empregar medidas preventivas na relação exclusiva e as ações que adotarão para modificar o comportamento do casal serão efetivas, de maneira que elas possam preservar sua saúde, mesmo diante de um relacionamento extralar de seu companheiro. Dessa forma seu forte senso de auto-eficácia se fará presente.

\section{REFLETINDO SOBRE OS DADOS}

A análise dos dados nos permitiu verificar que o grupo cultural representado neste estudo é formado por famílias, cujos membros são provenientes de várias regiões do país, com predominância dos Estados do Nordeste, ou descendem destes migrantes. Dentre as mulheres, a grande maioria iniciou atividade sexual antes dos vinte anos de idade e teve apenas um parceiro sexual até o momento do estudo. Raras são as mulheres com múltiplos parceiros. Esta constatação reforça a característica de juventude das famílias constituídas e coloca a mulher à mercê de um único homem, seu companheiro em uma relação exclusiva.

Estes achados desenham a dimensão dos graus de risco a que a mulher desta comunidade está exposta em relação à transmissão do HIV em seu cotidiano. 
Cabe ressaltar que a análise dos dados culturais sob a ótica do Modelo de Crenças em Saúde nos permitiu alcançar os objetivos do estudo, complementando a análise etnográfica efetuada diante dos dados coletados.

Concordamos com GOOD(1996) quando afirma que o emprego do Modelo de Crenças em Saúde mostra que o mesmo fornece uma concepção limitada da cultura e da ação humana sob estudo. Dentre outras afirmações, este autor reforça a concepção do Modelo e sua aplicação, ambos direcionados, especificamente, para auxiliar especialistas em saúde pública a convencer as pessoas a agirem mais racionalmente em relação à própria saúde. Paralelamente afirma que os autores de pesquisas realizadas sob sua ótica analisam as crenças em saúde dos indivíduos tendo como parâmetro o conhecimento biomédico. Este fato reduziria o conjunto de proposições mantidas pelo indivíduo em sua cultura particular.

Embora concordando com este autor quanto à análise dos estudos realizados até o momento, acreditamos que a realização de pesquisas feitas com metodologias qualitativas reduzam sua deficiência. Assim, neste estudo, realizamos a análise dos dados com base no método etnográfico, complementada pela análise sob a ótica do Modelo de Crenças em Saúde, foco deste texto. Visamos obter maior aprofundamento dos resultados e contribuir para o enriquecimento do referido Modelo.

Os resultados obtidos neste trabalho mostraram-nos que a mulher da comunidade estudada, diante da possibilidade de infecção pelo HIV, estará motivada a desenvolver sua auto-eficácia em beneficio próprio somente diante do conhecimento da infidelidade do companheiro. Frente a esta situação, ela passa a ter percepção aumentada de sua suscetibilidade e de sua severidade para a AIDS. Ao avaliar a relação barreiras a transpor e beneficios esperados percebe que, sob tal condição, estes apresentam maior poder para sua tomada de decisão e, portanto, motiva-se a agir. Acreditamos que esta característica cultural arraigada na relação familiar das mulheres pode estar contribuindo para a expansão da AIDS no país.

Estamos certas de que ações de atenção à saúde que reconheçam o aspecto cultural que permeia a relação do casal e que identifiquem a mulher como ponto vulnerável na cadeia de transmissão do HIV, interferindo junto ao casal para modificar esta condição, devem receber apoio e reforço dos profissionais de saúde.

\section{REFERÊNCIAS BIBLIOGRÁFICAS}

BARBOSA, RM. Feminino e AIDS. In: PARKER, R,; GALVÃO, J. (org) Quebrando o silêncio: mulheres e AIDS no Brasil. Rio de Janeiro, Relume-Dumará, 1996. Cap. 8, p.153-68.

BARBOSA, RM.; VILLELA, WV. A trajetória feminina da AIDS. In: PARKER, R; GALVAO, J. (org.) Quebrando o silêncio: mulheres e AIDS no Brasil. Rio de Janeiro, Relume-Dumará, 1996. Cap, 1, p.17-32.

BASTOS, C et al. Introdução. In: PARKER, R, et al, A AIDS no Brasil: 1982-1992. Rio de Janeiro, Relume-Dumará, 1994. Cap. 1, p, 13-56.

BOLETIM EPIDEMIOLÓGICO AIDS. Programa DST/AIDS. Secretaria de Estado da Saúde de São Paulo, v.16, n.1, 1998.

CASTILHO, EA.; SZWARCWALD, CL. Situação da AIDS no Brasil. Diag Tratamento, v.2, n.3, p.17-20, 1997.

GOOD, BJ. Medicine, rationality and experience: na anthropological perspective, New York, Cambridge, 1990. p.2564: Illness representations in medical anthropology: a reading of the field.

GUALDA, DMR,; MERIGHI, MAB,; OLIVEIRA, SMJV. Abordagens qualitativas: sua contribuição para a enfermagem. Rev Esc Enf USP, v.29, n.3, p.29'7-309, 1995.

GUIMARÃES, K. Nas raízes do silêncio: a representação cultural da sexualidade feminina e a prevenção do HIV/AIDS. In: PARKER, R.; GALVÃO, J, (org.) Quebrando o silêncio: mulheres e AIDS no Brasil. Rio de Janeiro, Relume-Dumará, 1996. Cap.5, p.89-113.

HAMMERSLEY, M.; ATKINSON, P Ethnography: principles in practice. London, Routledge, 1990.

LÜDKE, M.; ANDRÉ, MEDA. Pesquisa em educação: abordagens qualitativas. São Paulo, EPU, 1986,

STREUBERT, HJ.; CARPENTER, DR. Qualitative research in nursing: advancing the humanistic imperative. Philadelphia, L: Lippincott; 1995, 